\title{
PERBEDAAN PENINGKATAN HASIL BELAJAR EKONOMI DENGAN \\ MENERAPKAN MODEL COOPERATIF TIPE NHT (NUMBERED HEAD TOGETHER) DAN TIPE IOC (INSIDE OUTSIDE CIRCLE) PADA PESERTA DIDIK SMA MUHAMMADIYAH 1 PALANGKARAYA
}

\author{
Oleh: Agung Riadin* dan Muhammad Jailani**
}

agungriadin29@gmail.com

\begin{abstract}
ABSTRAK
Penelitian ini bertujuan untuk mengetahui dan menganalisis hasil pembelajaran dengan penggabungan model cooperatiftipe NHT (numbered head together) dan tipe IOC (inside outside circle) terhadap hasil belajar ekonomi siswa SMA Muhammadiyah 1 Palangkaraya. Teknik analisis data yang digunakan dalam penelitian ini adalah teknik analisis data dengan menggunakan Wilcoxon signed rank test. Kesimpulan yang dapat diambil berdasarkan hasil penelitian ini yaitu: model cooperatif tipe NHT (numbered head together) terbukti efektif untuk meningkatkan hasil belajar ekonomi siswa SMA Muhammadiyah 1 Palangkaraya, model cooperatif tipe IOC (inside outside circle) terbukti efektif meningkatkan hasil belajar ekonomi siswa SMA Muhammadiyah 1 Palangkaraya, penggabungan model cooperatif tipe NHT (numbered head together) dan tipe IOC (inside outside circle) efektif terhadap hasil belajar ekonomi siswa SMA Muhammadiyah 1 Palangkaraya.
\end{abstract}

Kata Kunci: Hasil Belajar Ekonomi, Cooperatif, Tipe NHT (Numbered Head Together), Tipe IOC (Inside Outside Circle)

\begin{abstract}
This study aims to determine and analyze learning outcomes by combining NHT (numbered head together) and IOC (inside outside circle) cooperative learning models on the economic learning outcomes of Palangkaraya Muhammadiyah 1 High School students. The data analysis technique used in this study was a data analysis technique using the Wilcoxon signed rank test. The conclusions that can be drawn based on the results of this study are: the NHT (numbered head together) cooperative model has proven to be effective in improving the economic learning outcomes of students of Muhammadiyah 1 Palangkaraya High School, the cooperative model of the IOC type (inside outside circle) has been proven to effectively improve the economic learning outcomes of Muhammadiyah 1 High School students Palangkaraya, the merging of the NHT (numbered head together) and IOC (inside outside circle) cooperative model is effective on the economic learning outcomes of Palangkaraya 1 Muhammadiyah high school students.
\end{abstract}

Keywords: Economic Learning Outcomes, Cooperative, NHT (Numbered Head Together) Type, IOC Type (Inside Outside Circle) 


\section{PENDAHULUAN}

Hasil belajar dapat di jelaskan dengan memahami dua kata yang membentuknya, yaitu "hasil" dan "belajar". Pengertian hasil (product) menunjuk pada suatu perolehan akibat dilakukannya suatu aktivitas atau proses yang mengakibatkan berubahnya input secara fungsional. Hasil produksi adalah perolehan yang didapatkan karena adanya kegiatan mengubah bahan (raw materials) menjadi barang jadi (finished goods).

Hasil belajar siswa pada dasarnya adalah perubahan tingkah laku. Tingkah laku sebagai hasil belajar dalam pengertian yang luas mencakup bidang kognitif, afektif dan psikomotoris. Setiap proses belajar yang dilaksanakan oleh peserta didik akan menghasilkan hasil belajar. Di dalam proses pembelajaran, guru sebagai pengajar sekaligus pendidik memegang peranan dan tanggung jawab yang besar dalam rangka membantu meningkatkan keberhasilan peserta didik dipengaruhi oleh kualitas pengajaran dan faktor intern dari siswa itu sendiri.

Menurut Abdurrahman

(2003) menyatakan bahwa Hasil belajar adalah kemampuan yang diperoleh anak setelah melalui kegiatan. Belajar itu sendiri merupakan proses dari seseorang yang berusaha untuk memperoleh suatu bentuk perubahan prilaku yang relatif menetap. Dalamkegiatan yang terprogram dan terkontrol yang disebut kegiatan pembelajaran atau kegiataninstruksional, tujuan telah ditetapkan lebih dahulu oleh guru.

Hasil belajar yang baik hanya dicapai melalui proses belajar yang baik pula. Jika proses belajar tidak optimal sangat sulit diharapkan terjadinya hasil belajar yang baik. Penilaian hasil belajar mengisyaratkan hasil belajar sebagai program atau objek yang menjadi sasaran penilaian. Menurut Sudjana, hasil belajar sebagai objek penilaian dapat di bedakan kedalam beberapa kategori, antara lain keterampilan dan kebiasaan, pengetahuan dan pengertian, sikap dan cita-cita.

Senada dengan pendapat yang di kemukakan oleh Sudjana, Dr. Purwanto mengatakan hasil belajar adalah perubahan prilaku disebabkan karena dia mencapai penguasaan atas sejumlah bahan yang diberikan dalam proses belajar mengajar. Pencapaian itu di dasarkan atas tujuan yang telah di tetapkan. Hasil belajar itu dapat berupa perubahan dalam aspek kognitif, afektif dan psikomotorik. Melihat pendapat yang di kemukakan oleh kedua para ahli tersebut maka dapat disimpulkan bahwa hasil belajar adalah perubahan tingkah laku yang terjadi setelah mengikuti proses belajar mengajar disekolah yang sesuai dengan tujuan yang telah ditetapkan. Perubaan tingkah laku yang diharapkan setelah mengalami proses belajar mengajar tersebut meliputi tiga domain, yaitu kognitif, afektif dan psikomotor. Hasil belajar adalah tingkah laku yang tidak tahu menjadi tahu, timbulnya pengertian baru, perubahan sikap, keterampilan, menghargai perkembangan sifat-sifat sosial, emosional dan pertumbuhan jasmani. Hasil belajar adalah kemampuankemampuan yang dimiliki siswa setelah ia menerima pengalaman belajar.

Berdasarkan hasil observasi dan hasil pre-test awal peneliti menemukan bahwa hasil belajar sebagian siswa SMA Muhammadiyah 1 Palangkaraya khususnya pada mata pelajaran ekonomi 
memiliki nilai rata-rata sedikit di atas nilai KKM (Kriteria Ketuntasan Minimal) yaitu sebesar 6,5. Sedangkan nilai KKM mata pelajaran ekonomi di SMA Muhammadiyah 1 Palangkaraya standarnya adalah 6,0. Nilai rata-rata yang dimiliki sebagian siswa tersebut memang tidak berada di bawah nilai KKM, namun hal tersebut dapat menjadi tolok ukur sejauh mana siswa mampu menerima dan menyerap pembelajaran khususnya pada mata pelajaran ekonomi. Nilai rata-rata hasil belajar tersebut menjadi acuan bagi peneliti untuk mengkaji kembali dan menguji metode pembelajaran yang berbeda yang akan diberikan kepada siswa SMA Muhammadiyah 1 Palangkaraya dalam hal peningkatan mutu dan hasil belajar ekonomi siswa SMA Muhammadiyah 1 Palangkaraya.

Dari hasil observasi awal tersebut maka dirasa perlu untuk dilakukan penelitian dengan menguji metode pembelajaran yang berbeda dalam hal peningkatan hasil belajar ekonomi siswa SMA Muhammadiyah 1 Palangkaraya.

Menurut Ernest Chang dan Don Simpson (1997:89) yang dikutip oleh Iskandar bahwa model pembelajaran adalah suatu cara untuk menghadapi tuntutan masa depan yang penuh tantangan dan perubahan. Sedangkan menurut Trianto (2010: 51), menyebutkan bahwa model pembelajaran adalah suatu perencanaan atau pola yang digunakan sebagai pedoman dalam merencanakan pembelajaran di kelas atau pembelajaran tutorial. Model pembelajaran mengacu pada pendekatan pembelajaran yang akan digunakan, termasuk di dalamnya tujuan-tujuan pengajaran, tahap-tahap dalam kegiatan pembelajaran, lingkungan pembelajaran, dan pengelolaan kelas.

Selanjutnya metode pembelajaran menurut Djamarah (2006:46) adalah suatu cara yang dipergunakan untuk mencapai tujuan yang telah ditetapkan. Dalam kegiatan belajar mengajar, metode diperlukan oleh guru agar penggunaannya bervariasi sesuai yang ingin dicapai setelah pengajaran berakhir.

Salah satu komponen yang turut serta memberikan pengaruh terhadap kesuksesan suatu proses pembelajaran adalah penerapan model pembelajaran yang relevan dengan bidang kajian yang dibelajarkan. Suprijono (2011: 58) menegaskan pembelajaran yang dapat memacu siswa berinteraksi dengan baik dengan siswa lainnya, dapat dilakukan guru dengan cara menerapkan model pembelajaran kooperatif.

$$
\text { Menurut Slavin }
$$
pembelajaran kooperatif adalah cara siswa bekerjasama dalam tim dengan anggota yang heterogen. Trianto, (2009: 56) menjelaskan bahwa pembelajaran kooperatif merupakan langkah untuk mempermudah siswa dalam memahami konsep. Melalui pembelajaran kooperatif siswa akan berdiskusi saling membantu dalam memahami konsep sehingga tercapailah suatu ketuntasan belajar. Menurut Depdiknas, melalui pembelajaran kooperatif siswa mampu meningkatkan kemampuan akademik, menerima segala bentuk perbedaan teman-temannya, mempunyai jiwa sosial yang tinggi. Dari tiga pendapat mengenai tujuan pembelajaran kooperatif, dapat dirumuskan bahwa pada hakikatnya pembelajaran kooperatif bertujuan meningkatkan kemampuan akademik 
siswa, menumbuhkan rasa toleransi, dan meningkatkan keterampilan sosial.

Salah satu model pembelajaran yang berpotensi dapat diterapkan dalam membelajarkan konsep-konsep ekonomi secara kolaboratif adalah model NHT (Numbered Head Together). Huda (2011: 203), mengemukakan diskusi kelompok dengan menggunakan model pembelajaran tipe NHT (Numbered Head Together) dapat memberikan peluang kepada siswa untuk saling bertukar pikiran atau pendapat dan mencari jawaban yang paling tepat secara kolaboratif. Dalam hal ini, siswa aktif dalam memecahkan soal yang diberikan guru.

Model pembelajaran kooperatif lainnya adalah model pembelajaran tipe inside outside circle. Model pembelajaran inside outside circle adalah model pembelajaran dengan sistem lingkaran kecil dan lingkaran besar yang diawali dengan pembentukan kelompok besar dalam kelas yang terdiri dari kelompok lingkaran dalam dan kelompok lingkaran luar (Rusman, 2013:21). Model pembelajaran inside outside circle dikembangkan oleh Spencer Kagan (1990). Model pembelajaran ini memungkinkan siswa untuk saling berbagi informasi pada waktu yang bersamaan (Huda, 2013:144) dan hal tersebut dapat dipahami bahwa model pembelajaran dengan tipe inside outside circle merupakan model pembelajaran kooperatif yang juga dapat digunakan dalam pembelajaran mata pelajaran ekonomi yang memacu interaksi siswa dengan siswa lain dalam kelompoknya dan memacu jiwa kompetisi sehingga berpotensi untuk meningkatkan kemampuan dan kreatifitas mereka dalam mengikuti pembelajaran ekonomi di sekolah.

Menurut Wati menjelaskan bahwa keunggulan model pembelajaran ini adalah adanya struktur yang jelas dan memungkinkan siswa untuk berbagi informasi dengan pasangan yang berbeda secara singkat dan teratur. Selain itu, model pembelajaran tipe inside outside circle memberikan banyak kesempatan pada siswa untuk mengolah informasi dan meningkatkan pemahaman konsep ekonomi. Maka berdasarkan uraian di atas diduga bahwa model pembelajaran inside outside circle juga dapat meningkatkan pemahaman konsep ekonomi siswa.

\section{1) Model Pembelajaran NHT (Numbered Head Together)}

Menurut Ibrahim, dkk, 2000 dalam Sumarjito (2011:3) menjelaskan bahwa numbered heads together (NHT) merupakan metode pembelajaran yang dikembangkan untuk melibatkan banyak siswa dalam menelaah materi yang tercakup dalam suatu pelajaran dan mengukur pemahaman mereka terhadap materi pelajaran tersebut. Sementara itu Menurut Lie (2010:59) bahwa yang dimaksud dengan metode belajar mengajar kepala bernomor (numbered heads) adalah memberikan kesempatan kepada siswa untuk saling membagikan ide-ide dan mempertimbangkan jawaban yang paling tepat.

Numbered heads together (NHT) atau penomoran berpikir bersama dikembangkan oleh Spencer Kagan (1992). Model pembelajaran NHT memberi kesempatan siswa saling bertukar gagasan dan menentukan jawaban yang paling tepat (Miftahul Huda, 2011: 138). Ridwan, (2015: 44) 
mengungkapkan NHT merupakan model pembelajaran kooperatif yang menuntut siswa untuk berpikir bersama kelompoknya. Setiap anggota kelompok diberi nomor dan berkesempatan menjawab pertanyaan dari guru. Unsurunsur yang yang terkandung dalam model NHT adalah sebagai berikut:

1) Sintagmatis

Menurut Trianto, (2009: 82) penerapan model NHT dilakukan melalui enam fase:

a. Fase 1: Penomoran.

b. Fase 2: Pengajuan pertanyaan.

c. Fase 3: Berpikir bersama.

d. Fase 4: Menjawab pertanyaan.

2) Prinsip Reaksi

Menggambarkan pola tingkah laku guru dalam memperlakukan siswa ketika belajar. Peran guru dalam pembelajaran kooperatif tipe NHT adalah sebagai fasilitator yang terlibat langsung dalam pembelajaran. Guru juga berperan sebagai pembimbing setiap kelompok dengan menciptakan suasana yang hangat dan menyenangkan. Guru menjelaskan tentang tata cara/aturan pembelajaran yang akan berlangsung dengan jelas sehingga semua siswa dapat memahami dengan baik.

Guru memfasilitasi dan mengarahkan siswa dalam membentuk kelompok dengan transisi yang efisien. Setelah terbentuk kelompok-kelompok, guru memberikan arahan tentang cara diskusi kelompok; dimana guru mengajukan pertanyaan kepada siswa yang mempunyai kepala bernomor sama secara acak kemudian guru mengamati siswa dalam diskusi. Setelah siswa memaparkan jawabannya, guru melakukan pemantapan materi dan klarifikasi apabila siswa mengalami miskonsepsi.

3) Sistem Sosial

Sistem sosial yang dimaksud yaitu norma yang terdapat dalam model ini berlandaskan pada proses demokrasi dan keputusan kelompok. Guru tidak sepenuhnya menjadi pusat perhatian, namun ada kalanya perhatian tersebut tertuju pada siswa. Sistem sosial dalam pembelajaran ini berupa sikap saling membantu antarteman dalam kelompok. Siswa saling bahumembahu dalam mencari jawaban yang paling tepat atas pertanyaan yang diterima. Ketika berlangsungnya diskusi untuk mencari jawaban yang tepat, setiap anggota kelompok pasti mempunyai jawaban atau gagasan yang berbeda-beda. Dalam hal ini tentu saja harus ada pendapat yang diterima dan ditolak. Disinilah siswa akan belajar saling menghargai pendapat yang dikemukakan oleh teman. Selain itu, ketika jawaban dari semua kelompok dibacakan dan dikoreksi, akan terlihat kelompok mana yang mempunyai prestasi tertinggi dan terendah. Kelompok yang mempunyai prestasi rendah, akan belajar menerima kekalahan kelompok sendiri dan menghargai kemenangan kelompok lain.

4) Daya Dukung

Dalam pembelajaran

kooperatif NHT salah satunya 
adalah kondisi lingkungan fisik sesuai kebutuhan siswa dalam pembelajaran seperti kebersihan dan kenyamanan ruang kelas, ketersediaan sarana dan prasarana yang memadai untuk menunjang proses pembelajaran yang berupa meja, kursi, papan tulis, dll.

Selain itu, guru harus mempersiapkan bahan ajar yang digunakan yaitu berupa materi pecahan untuk siswa lengkap dengan Lembar Kerja Siswa (LKS) atau berupa pertanyaan yang siap diajukan kepada siswa dan sumber belajar (buku dan lingkungan sekitar siswa) yang berkaitan dengan materi pecahan. Tidak lupa guru harus menyusun Rencana Pelaksanaan Pembelajaran (RPP) sebelum melaksanakan kegiatan pembelajaran.

5) Dampak Instruksional dan Dampak Pengiring.

Dampak instruksional merupakan hasil belajar yang harus dikuasai siswa berupa kemampuankemampuan siswa setelah menerima atau menyelesaikan pengalaman belajarnya. Dampak instruksional setelah siswa mengikuti pembelajaran matematika dengan menggunakan model pembelajaran kooperatif tipe NHT yaitu proses pembentukan dan pengelolaan kelompok dapat dilakukan secara efisien sesuai minat siswa namun masih dalam kontrol guru; sehingga proses pembelajaran secara berkelompok dapat berjalan dengan baik dan mencapai tujuan yang diharapkan.
Melalui model pembelajaran kooperatif tipe NHT ini, diharapkan dapat membiasakan siswa untuk membangun pengetahuannya melalui diskusi kelompok, sehingga siswa akan lebih termotivasi untuk belajar. Melalui proses kerjasama dalam kelompok, siswa berlatih untuk disiplin dan tanggung jawab dari masing-masing anggota kelompok, sehingga semua anggota kelompok dapat berpartisipasi aktif dalam diskusi.

\section{2) Model Pembelajaran IOC (Inside Outside Circle)}

Model pembelajaran inside outside circle adalah model pembelajaran dengan sistem lingkaran kecil dan lingkaran besar yang diawali dengan pembentukan kelompok besar dalam kelas yang terdiri dari kelompok lingkaran dalam dan kelompok lingkaran luar. Sehingga dapat menciptakan variasi ketika proses belajar mengajar di kelas dan dapat membantu meningkatkan pemahaman siswa (Ngalimin, 2012:90). Sejalan dengan Ngalimin (2012), Rusman (2013) juga menjelaskan bahwa model pembelajaran inside outside circle merupakan model pembelajaran dengan sistem lingkaran kecil dan lingkaran besar yang diawali dengan pembentukan kelompok besar dalam kelas yang terdiri dari kelompok lingkaran dalam dan kelompok lingkaran luar. Model pembelajaran inside outside circle dikembangkan oleh Spencer Kagan (1990). Model pembelajaran ini memungkinkan siswa untuk saling berbagi informasi pada waktu yang bersamaan (Huda, 2013:144). Adapun langkah-langkah model pembelajaran inside outside circle adalah seabagai berikut: 
a. Guru membagi siswa menjadi kelompok yang terdiri dari 3-4 orang;

b. Tiap-tiap kelompok mendapat tugas mencari informasi berdasarkan pembagian tugas dari guru;

c. Setiap kelompok belajar mandiri, mencari informasi berdasarkan tugas yang diberikan;

d. Setelah selesai, seluruh siswa berkumpul membaur (tidak berdasarkan kelompok);

e. Separuh kelas lalu berdiri membentuk lingkaran kecil dan menghadap keluar;

f. Separuh kelas lainnya membentuk lingkaran diluar lingkaran pertama, menghadap kedalam;

g. Dua siswa yang berpasangan dari lingkaran kecil dan besar berbagi informasi. Pertukaran informasi ini bisa dilakukan oleh semua pasangan dalam waktu yang bersamaan;

h. Kemudian siswa berada di lingkaran kecil diam ditempat, sementara siswa yang berada di lingkaran besar bergeser satu atau dua langkah searah jarum jam;

i. Sekarang giliran siswa berada di lingkaran besar berbagi informasi. Demikian seterusnya, sampai seluruh siswa selesai berbagi informasi;

j. Pergerakan baru dihentikan jika anggota kelompok lingkaran dalam dan luar sebagai pasangan asal bertemu kembali; dan

k. Guru memberikan evaluasi atau latihan soal mandiri.

Menurut Wati (2014:2) keunggulan model pembelajaran ini adalah adanya struktur yang jelas dan memungkinkan siswa untuk berbagi informasi dengan pasangan yang berbeda secara singkat dan teratur. Selain itu, model pembelajaran tipe inside outside circle memberikan banyak kesempatan pada siswa untuk mengolah informasi dan meningkatkan pemahaman konsep ekonomi.

\section{METODE PENELITIAN}

Penelitian merupakan kegiatan ilmiah yang ditempuh oleh seorang peneliti untuk mendapatkan suatu hasil atau pemecahan masalah dari serangkaian proses yang sistematis. Maka dari itu, dalam proses meneliti diperlukan metode tertentu yang menjadi bukti bahwa penelitian dilakukan secara ilmiah untuk mendapatkan data yang sesuai dengan tujuan serta fungsinya. Pada bab ini disajikan desain penelitian, subjek penelitian, variabel penelitian, teknik dan instrumen pengumpul data, uji validitas dan reliabilitas, dan teknik analisis data.

\section{a. Desain Penelitian}

Desain penelitian diperlukan untuk memberikan pedoman kepada peneliti agar dapat merencanakan dan melaksanaan penelitian serta membantu dalam pengumpulan dan menganalisis data. Penelitian ini menggunakan pendekatan kuantitatif dengan metode eksperimen. Cresswell (2015: 576) menyatakan penelitian eksperimen adalah cara untuk menguji suatu ide untuk menentukan ide tersebut dapat mempengaruhi hasil atau variabel dependen. Dalam penelitian ini desain eksperimen yang digunakan "Randomized Pretest-Posttest Comparasion Group” 
Desain penelitian ini dinilai paling fleksibel dan paling mungkin untuk dilaksanakan pada ranah pendidikan dan penelitian sosial. Menurut Purwanto (2013: 117) menyebutkan bahwa desain randomized pretest-postest comparasion group ini tidak ada perlakuan yang diberikan kepada kelompok kontrol. Tidak diberikannya perlakuan kepada kelompok kontrol dipandang kurang manusiawi. Pada desain randomized pretest-postest comparasion group, kelompok pembanding (yang berfungsi sebagai kelompok kontrol) diberikan perlakuan berupa variasi dari variabel perlakuan, jumlahnya bisa dua atau lebih.

Penelitian ini menggunakan rancangan eksperimen dengan desain Randomized Pretest-Posttest Comparison Group Design. Desain ini merupakan perluasan dari single-group pretestposttest design. Menurut Purwanto (2016: 131) menyebutkan bahwa desain Randomized Pretest-Posttest Comparasion Group merupakan desain yang paling baik dalam mengontrol ancaman validitas internal. Designnya dapat digambarkan sebagai berikut:

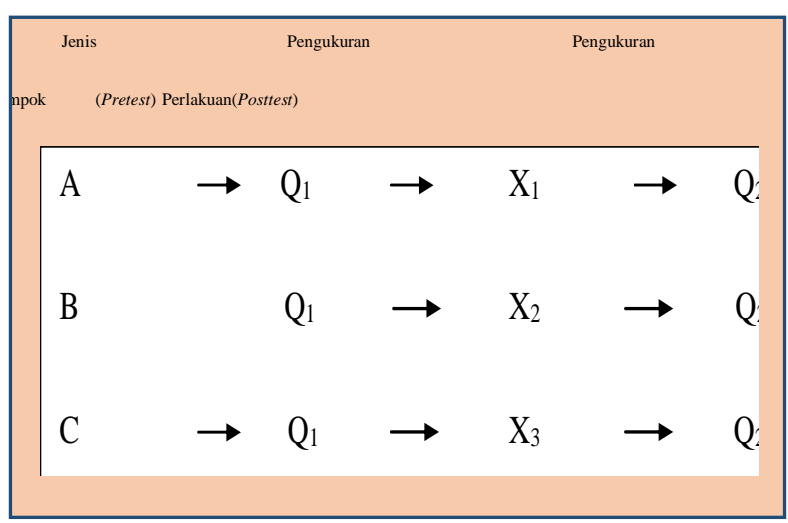

Gambar 1. Bagan Desain Penelitian Randomized Pretest-Posttest Comparasion Group b. Populasi dan Subjek

Populasi meruapakan sekelompok individu yang memiliki karakteristik sama (Edmons dan Kennedy, 2013: 15). Populasi dalam penelitian ini adalah seluruh siswa SMA Muhammadiyah 1 Palangkaraya.Subjek penelitian dalam penelitian ini adalah siswa yang memiliki hasil pre-test nilai ekonomi yang sedikit di atas nilai standart KKM.

c. Variabel Penelitian

Variabel merupakan suatu atribut atau sifat atau nilai dari orang, objek atau kegiatan yang mempunyai variasi tertentu yang ditetapkan oleh peneliti untuk dipelajari kemudian ditarik kesimpulan (Sugiyono, 2007: 3 ). Dalam penelitian ini variabel yang digunakan adalah variabel hasil belajar ekonomi sebagai variabel dependen, model pembelajaran cooperatif tipe NHT sebagai variabel independen $\left(\mathrm{X}_{1}\right)$, dan model pembelajaran cooperatif IOC sebagai variabel independen $\left(\mathrm{X}_{2}\right)$. Berikut hubungan antar variabel dalam penelitian ini:

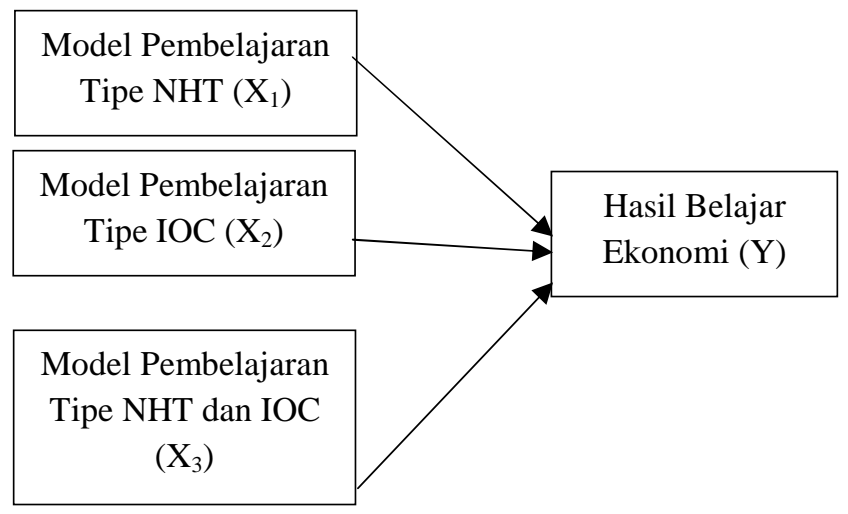

\section{Gambar 2. Hubungan Antar Variabel}

d. Uji Validitas

Validitas adalah seberapa jauh alat ukur dapat mengungkap dengan benar gejala atau sebagian gejala yang hendak 
diukur, artinya alat ukur tersebut mengukur apa yang seharusnya diukur. Uji validitas pada penelitian ini menggunakan uji validitas item. Hal ini dilakukan agar benar-benar diperoleh suatu instrumen yang bisa mengukur dan mengungkap aspek agresivitas responden. Instrumen perlu untuk diuji cobakan kepada subjek dengan karakteristik yang hampir sama dengan subjek penelitian. Setelah itu menghitung validitas item dengan menggunakan rumus Product MomentPearson Correlation dan perhitungannya akan dibantu dengan program IBM SPSS Statistik 23. Kriteria item dikatakan valid jika nilai koefisien pearson correlation $>0,3$.

e. Uji Reliabilitas

Reliabilitas berarti bahwa skor dari suatu instrument itu stabil dan konsisten, skor seharusnya tetap hampir sama ketika peneliti mengadministrasikan instrument itu berulang kali dalam waktu yang berbeda. (Creswell. 2013). Menurut Purwanto (2016) mendefinisikan reabilitas adalah melihat tingkat sejauh mana skor tes konsisten (concictence), dapat di percaya (dependable) dan dapat di ulang (reapetable). Dengan kata lain reliabilitas merupakan hasil dari instrument yang dapat dipercaya dan dianggap sudah baik. Dalam penelitian ini, uji reliabelitas akan dilakukan uji koefesien Alpha Cronbach dengan bantuan program IBM SPSS 23.0 for windows.

\section{f. Teknik Analisis Data}

Teknik analisis data yang digunakan dalam penelitian ini adalah teknik analisis data dengan menggunakan Uji Wilcoxon. Wilcoxon signed rank test merupakan uji non parametrik yang digunakan untuk menganalisis data berpasangan. Data dikatakan berpasangan jika terdapat dua perlakuan berbeda yang diterapkan pada kelompok yang sama. Wilcoxon signed rank test juga digunakan pada jenis data ordinal tetapi tidak beristribusi nornal. Dalam analisis ini memiliki tujuan untuk mengkaji hasil perubahan skor antara pretest dan posttest pada masing-masing kelompok treatrment. Perhitungannya akan dibantu dengan program IBM SPSS Statistik 24.

\section{HASIL DAN PEMBAHASAN}

Data yang diperoleh dari pengisian soal-soal mata pelajaran ekonomi akan dianalisis melalui analisis deskriptif. Analisis deskriftif bertujuan untuk memberikan penjelasan variabel hasil belajar ekonomi dengan menerapkan model cooperatif tipe nht (numbered head together) dan tipe ioc (inside outside circle) pada peserta didik SMA Muhammadiyah 1 Palangkaraya. Berikut deskripsi data yang diperoleh:

1. Hasil Pre-Test\&Post-Test Belajar Ekonomi model Cooperatif Tipe NHT

Tabel 1. Pre-Test \& Post-Test Belajar Ekonomi model Cooperatif Tipe NHT

\begin{tabular}{|c|l|c|c|}
\hline No. & $\begin{array}{l}\text { Inisial } \\
\text { Sampel }\end{array}$ & $\begin{array}{l}\text { Hasil } \\
\text { Pre-Test }\end{array}$ & $\begin{array}{l}\text { Hasil } \\
\text { Post-Test }\end{array}$ \\
\hline 1. & $\mathrm{As}$ & 61 & 70 \\
\hline 2. & $\mathrm{Ad}$ & 60 & 71 \\
\hline 3. & $\mathrm{Sd}$ & 59 & 75 \\
\hline $\mathbf{4 .}$ & $\mathrm{De}$ & 58 & 71 \\
\hline 5. & $\mathrm{Fa}$ & 40 & 69 \\
\hline $\mathbf{6 .}$ & $\mathrm{Ba}$ & 62 & 83 \\
\hline 7. & $\mathrm{Ri}$ & 63 & 79 \\
\hline $\mathbf{1 0 .}$ & To & 63 & 80 \\
\hline \multicolumn{2}{|l|}{ Jumlah } & 466 & 598 \\
\hline
\end{tabular}




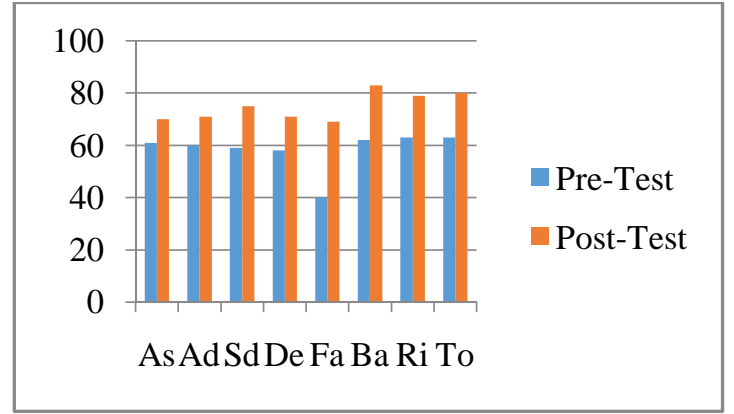

Diagram 1. Hasil Pre-Test \& Post-Test Hasil Belajar Ekonomi dengan Model NHT

2. Hasil Pre-Test\&Post-Test Belajar Ekonomi model Cooperatif Tipe IOC

Tabel 2. Pre-Test \& Post-Test Belajar Ekonomi model Cooperatif Tipe IOC

\begin{tabular}{|c|l|c|c|}
\hline No. & $\begin{array}{l}\text { Inisial } \\
\text { Sampel }\end{array}$ & $\begin{array}{l}\text { Hasil } \\
\text { Pre-Test }\end{array}$ & $\begin{array}{l}\text { Hasil } \\
\text { Post-Test }\end{array}$ \\
\hline 1. & $\mathrm{Da}$ & 55 & 75 \\
\hline 2. & $\mathrm{Ge}$ & 61 & 78 \\
\hline 3. & $\mathrm{Ba}$ & 55 & 79 \\
\hline 4. & $\mathrm{Ki}$ & 60 & 85 \\
\hline 5. & $\mathrm{La}$ & 64 & 89 \\
\hline 6. & $\mathrm{Je}$ & 70 & 79 \\
\hline 7. & $\mathrm{Ge}$ & 57 & 75 \\
\hline 10. & $\mathrm{Sa}$ & 61 & 80 \\
\hline \multicolumn{2}{|c|}{ Jumlah } & 483 & 640 \\
\hline
\end{tabular}

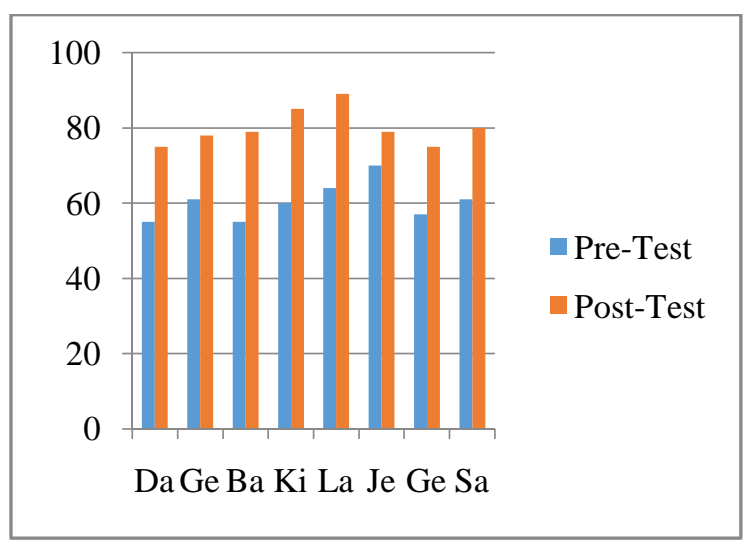

Diagram 2. Hasil Pre-Test \& Post-Test Hasil Belajar Ekonomi dengan Model IOC
3. Hasil Pre-Test\&Post-Test Belajar Ekonomi model Cooperatif Tipe NHT dan IOC

Tabel 3. Pre-Test \& Post-Test Belajar Ekonomi Model Cooperatif Tipe NHT \& IOC

\begin{tabular}{|c|l|c|c|}
\hline No. & $\begin{array}{l}\text { Inisial } \\
\text { Sampel }\end{array}$ & $\begin{array}{l}\text { Hasil } \\
\text { Pre-Test }\end{array}$ & $\begin{array}{l}\text { Hasil } \\
\text { Post-Test }\end{array}$ \\
\hline 1. & $\mathrm{Ra}$ & 55 & 75 \\
\hline 2. & $\mathrm{Re}$ & 65 & 78 \\
\hline 3. & $\mathrm{Di}$ & 63 & 80 \\
\hline $\mathbf{4 .}$ & $\mathrm{We}$ & 58 & 85 \\
\hline $\mathbf{5 .}$ & $\mathrm{Ag}$ & 61 & 80 \\
\hline 6. & $\mathrm{Ta}$ & 62 & 82 \\
\hline 7. & $\mathrm{Ha}$ & 70 & 90 \\
\hline 10. & $\mathrm{Bi}$ & 493 & 645 \\
\hline \multicolumn{2}{|c|}{ Jumlah } \\
\hline
\end{tabular}

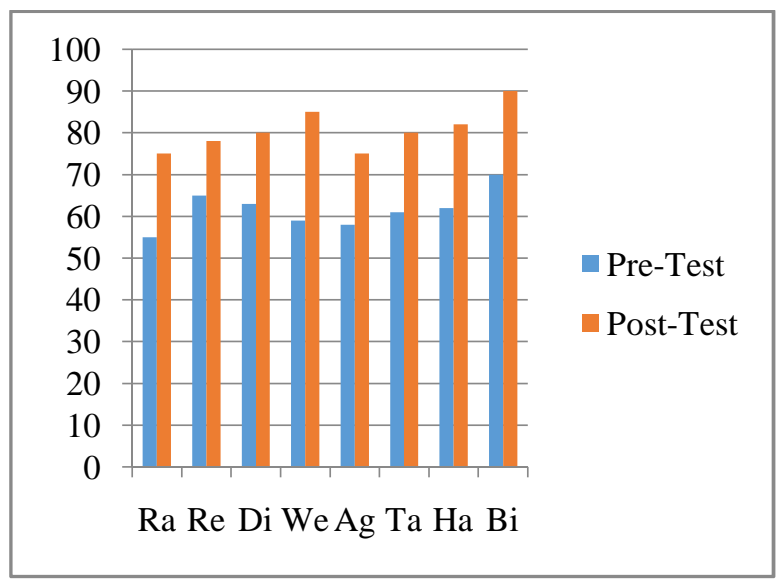

Diagram 3. Hasil Pre-Test \& Post-Test Hasil Belajar Ekonomi dengan Model NHT \& IOC

\section{KESIMPULAN}

Kesimpulan yang dapat diambil berdasarkan hasil penelitian ini yaitu : 
Model cooperatif tipe NHT (numbered head together) terbukti efektif untuk meningkatkan hasil belajar ekonomi siswa SMA Muhammadiyah 1 Palangkaraya.

Model cooperatif tipe IOC (inside outside circle) terbukti efektif meningkatkan hasil belajar ekonomi siswa SMA Muhammadiyah 1 Palangkaraya.

Penggabungan model cooperatif tipe NHT (numbered head together) dan tipe IOC (inside outside circle) efektifterhadap hasil belajar ekonomi siswa SMA Muhammadiyah 1 Palangkaraya.

\section{DAFTAR PUSTAKA}

Purwanto, Dr. M.Pd. 2009. Evaluasi Hasil Belajar. Pustaka Pelajar. Yogyakarta.

Abdurrahman, Mulyono. 2003. Pendidikan Bagi Anak Berkesulitan Belajar. Jakarta: Rineka Cipta.

Afandi, Muhammad, S, Pd., M. Pd., Chamalah, S. Pd. M. Pd., Wardani, Oktarina Puspita, S. Pd., M. Pd. 2013. Model dan Metode Pembelajaran di Sekolah.Unissula Press. Semarang.

Hamalik, Oemar. 2010. Proses Belajar Mengajar Mengajar. Jakarta: Bumi Aksara.

Huda, M. 2011. Cooperative Learning Metode, teknik, Struktur dan Model Penerapan. Yogyakarta: Pustaka Pelajar.

Lie, Anita. (2010). Cooperative Learning. Jakarta : PT Gramedia.

Slavin, R.E. 2011. Cooperative Learning: Teori, Risetdan Praktik.Bandung: Nusa Media
Sumarjito. (2011). Penggunaan Model Pembelajaran NHT Untuk Meningkatkan Hasil Belajar Biologi Kelas XI IPA SMA Islam 1 Prambanan Tahun Pelajaran 2009/2010. Jurnal 1-2.

Trianto. 2009. Mendesain Model Pembelajaran Inovatif-Progresif. Surabaya: Kencana. 